\title{
MicroRNA-296 targets AKT2 in pancreatic cancer and functions as a potential tumor suppressor
}

\author{
HAILING LI ${ }^{1}$, JILIN LI $^{2}$, BAOLIN SHI $^{3}$ and FENG CHEN ${ }^{4}$ \\ ${ }^{1}$ Department of Endocrinology, Weifang People's Hospital, Weifang, Shandong 261000; \\ ${ }^{2}$ Department of Medical Laboratory Medicine, Family Planning Guidance Center of Weifang, Weifang, Shandong 261061; \\ ${ }^{3}$ Department of Neurology, Weifang People's Hospital, Weifang, Shandong 261000; \\ ${ }^{4}$ Department of Endocrinology, Weifang Municipal Official Hospital, Weifang, Shandong 261041, P.R. China
}

Received January 16, 2016; Accepted January 9, 2017

DOI: $10.3892 / \mathrm{mmr} .2017 .6602$

\begin{abstract}
Although microRNA-296 (miR-296) has been studied in various types of human cancer, its expression, biological role and mechanism of action in pancreatic cancer remains to be elucidated. The aim of the current study was to investigate the expression level, possible roles and underlying molecular mechanisms of miR-296 in pancreatic cancer. The present study revealed that miR-296 is significantly downregulated in tissue from patients with pancreatic cancer and in human pancreatic carcinoma cell lines, when compared with matched healthy tissue and normal human pancreatic cell lines, respectively. In addition, restoration of miR-296 expression was revealed to inhibit the proliferation, migration and invasive activity of pancreatic cancer cells. Furthermore, bioinformatics analysis and a luciferase reporter assay validated the AKT2 gene as a direct target of miR-296 in pancreatic cancer. Reverse transcription-quantitative polymerase chain reaction and western blot analysis revealed that miR-296 was able to decrease AKT2 expression at the post-transcriptional level. Notably, the effects of AKT2 knockdown were similar to miR-296 overexpression in pancreatic cancer. In conclusion, the present findings indicate a role for miR-296 as a tumor suppressor in pancreatic cancer through directly targeting AKT2, thus suggesting that miR-296 may serve as a potential therapeutic target for the treatment of pancreatic cancer.
\end{abstract}

\section{Introduction}

Pancreatic cancer, which is one of the most invasive types of malignant tumor, is the sixth leading cause of mortality in China, the fourth leading cause of cancer-associated mortality in the United States, and has the worst prognosis among all

Correspondence to: Professor Feng Chen, Department of Endocrinology, Weifang Municipal Official Hospital, 2770 Shengli East Road, Weifang, Shandong 261041, P.R. China

E-mail: wmoh_fengchen@163.com

Key words: miR-296, pancreatic cancer, growth, metastasis, AKT2 solid cancers (1-3). It was previously estimated that 53,070 new cases of pancreatic cancer and 41,780 cases of mortality caused by pancreatic cancer would occur in the United States in 2016 (4). Several risk factors contributing to pancreatic carcinogenesis have been identified, including age, smoking, obesity and chronic pancreatitis (5-7). In the past few decades, great progress in cancer research has led to the discovery of novel diagnostic and surgical techniques. However, although these have served to improve morbidity and postoperative mortality, they have had no significant impact on survival (8). The overall 5 -year survival rate for all stages of pancreatic cancer is only $5 \%$, and the median survival time is $\sim 6$ months (9). The poor prognosis for patients with pancreatic cancer is mainly attributed to non-specific symptoms, aggressive growth, early and aggressive local invasion, metastatic potential, and resistance to chemotherapy and radiotherapy (10-12). Therefore, elucidation of the underlying mechanisms involved in pancreatic cancer pathogenesis, as well as the development of novel therapeutic treatments, is critical for improving the prognosis and therapeutic efficacy in patients with pancreatic cancer.

Recently, microRNAs (miRNAs), a novel group of endogenous, single-stranded, small, non-coding regulatory RNA molecules with a length of 18-24 nucleotides, have garnered attention (13). miRNAs decrease gene expression through targeting partial complementary elements in the $3^{\prime}$ untranslated regions (3'UTR) of their target genes, and function via two mechanisms: Degrading the expression of target genes and/or suppressing their translation (14). A single specific miRNA may regulate a large number of target genes, often targeting numerous components of complex intracellular networks (15). Key roles for miRNAs have been established in various biological processes, including cell proliferation, differentiation, metabolism and apoptosis, which contribute to the pathogenesis of several diseases, including cancer. Previous studies have demonstrated that the abnormal expression of miRNAs and their target genes is correlated with carcinogenesis and cancer progression (16-18). Numerous miRNAs have been reported to be up- or downregulated in pancreatic cancer, whereas the expression of specific miRNAs has been correlated with poor disease prognosis, thus demonstrating the potential of these molecules as novel therapeutic targets for cancer therapy (19-21). 
The present study aimed to investigate the pattern of expression, biological role and mechanism of action of a specific miRNA molecule, miR-296, in pancreatic cancer. In addition, it was revealed that AKT2 is a direct target gene of miR-296 in pancreatic cancer, indicating that miR-296 may hold potential as a molecular target in the treatment of pancreatic cancer.

\section{Materials and methods}

Clinical specimens. Human pancreatic cancer tissue samples from patients with pancreatic cancer ( 7 male and 5 female; age range, 39-68 years), and matched control normal tissue (7 male and 5 female; age range, 39-68 years) samples were obtained at Weifang People's Hospital (Weifang, China). These specimens were immediately snap-frozen and stored in liquid nitrogen until further processing. The present study was approved by the Ethics Committee of Weifang People's Hospital. Written informed consent was also obtained from all patients participating in the present study.

Cell lines, culture conditions and oligonucleotide transfection. Human pancreatic carcinoma cell lines PANC-1, BxPC-3, Capan-2,SW-1990 and AsPC-1, and the human normal pancreatic cell line HPDE6c7 were purchased from American Type Culture Collection (Manassas, VA, USA). HEK293T cells were obtained from the Shanghai Institute of Biochemistry and Cell Biology (Shanghai, China). All cells were cultured in Dulbecco's modified Eagle's medium (DMEM; Thermo Fisher Scientific, Inc., Waltham, MA, USA) supplemented with $10 \%$ fetal bovine serum (FBS; Thermo Fisher Scientific, Inc.), and maintained at $37^{\circ} \mathrm{C}$ in a $5 \% \mathrm{CO}_{2}$ atmosphere.

miR-296 mimics and negative controls (NC) were purchased from Shanghai GenePharma Co., Ltd. (Shanghai, China). AKT2 (5'-AGTGACCATGAATGACTTC-3') and NC (5'-TCTACGAGTCGCGGCATTC-3') small interfering RNA (siRNA) were obtained from Guangzhou RiboBio Co., Ltd. (Guangzhou, China). PANC-1 and Capan-2 cells were transfected with these oligonucleotides using Lipofectamine 2000 reagent (Invitrogen; Thermo Fisher Scientific, Inc.) as the delivery agent, following to the manufacturer's protocol.

$R N A$ isolation and reverse transcription quantitative-polymerase chain reaction ( $R T-q P C R)$. Total RNA was isolated from clinical specimens and cells using TRIzol reagent (Invitrogen; Thermo Fisher Scientific, Inc.) according to the manufacturer's protocol. Total RNA was reverse transcribed into cDNA using PrimeScript RT reagent kit (Takara Biotechnology Co., Ltd, Dalian, China), following to the manufacturer's protocol. qPCR analyses were performed on cDNA using SYBR Green Premix Ex Taq (Takara Biotechnology Co., Ltd.) as the fluorescent reporter probe. miR-296 expression was detected with Hairpin-it miRNA qPCR Quantitation kit (Shanghai GenePharma Co., Ltd.). The $20 \mu \mathrm{l}$ reaction system for qPCR contained $10 \mu \mathrm{l}$ SYBR Green I mix, $2 \mu \mathrm{l}$ forward primer, $2 \mu \mathrm{l}$ reverse primer and $4 \mu 1$ double distilled water. The thermocycling conditions for qRCR were as follows: $95^{\circ} \mathrm{C}$ for $30 \mathrm{sec} ; 40$ cycles of $95^{\circ} \mathrm{C}$ for $5 \mathrm{sec}$; and $60^{\circ} \mathrm{C}$ for $30 \mathrm{sec}$. The following primers were used: miR-296 forward, 5'-TGCCTA ATTCAGAGGGTTGG-3' and reverse, 5'-CTCCACTCCTGG CACACAG-3'; U6 forward, 5'-CTCGCTTCGGCAGCACA-3' and reverse, 5'-AACGCTTCACGAATTTGCGT-3'; AKT2 forward, 5'-TCCAGAACACCAGGCACCC-3' and reverse, 5'-ATTGTCCTCCAGCACCTCA-3'; and GAPDH forward, 5'-GCACCGTCAAGGCTGAGAAC-3' and reverse, 5'-TGG TGAAGACGCCAGTGGA-3'. RT-qPCR was performed in an ABI Prism 7700 Sequence Detector (Applied Biosystems; Thermo Fisher Scientific, Inc.). Relative expression levels of miR-296 and AKT2 mRNA were calculated using the the $2^{-\Delta \Delta \mathrm{Cq}}$ method (22) and the results were normalized to U6 expression for miR-296 and GAPDH expression for mRNA.

Cell Counting Kit 8 (CCK8) assay. Cell proliferation was evaluated with CCK8 (Dojindo Molecular Technologies, Inc., Kumamoto, Japan). Transfected cells were harvested and re-suspended into a single cell suspension. A total of $4 \times 10^{3}$ cells in $150 \mu$ l culture medium were seeded per well in 96-well plates. At various time-points after seeding (1, 2 and 3 days), cell proliferation was measured as follows: $10 \mu \mathrm{l}$ CCK8 assay solution was added to each well, and incubated at $37^{\circ} \mathrm{C}$ for $4 \mathrm{~h}$. The absorbance of the sample at $450 \mathrm{~nm}$ was measured using a multiwell spectrophotometer (BioTek Instruments, Inc., Winooski, VT, USA).

Transwell migration and invasion assays. The migratory and invasive capabilities of pancreatic cancer cells were assessed using Costar Transwell inserts (pore size, $8 \mu \mathrm{m}$; Corning Incorporated, Corning, NY, USA). The membranes were pre-coated with $40 \mu \mathrm{g} /$ well Matrigel (BD Biosciences, San Jose, CA, USA) for the invasion assay. A total of $48 \mathrm{~h}$ post-transfection, the cells were harvested and re-suspended into a single cell suspension in serum-free DMEM. Cells were seeded into the upper chambers of the plate at a density of $5 \times 10^{4}$ cells in $250 \mu \mathrm{l}$ serum-free medium; culture medium supplemented with $20 \%$ FBS was added to the lower chambers. After incubation for $48 \mathrm{~h}$ at $37^{\circ} \mathrm{C}$, the cells on the top of the membrane were removed carefully with cotton swabs. The cells on the lower membrane were fixed with methanol, stained with crystal violet and then counted under a light microscope (x200; Olympus Corporation, Tokyo, Japan) to calculate their relative numbers.

Western blot analysis. A total of $72 \mathrm{~h}$ post-transfection, the cells were collected and lysed in radioimmunoprecipitation assay lysis buffer supplemented with protease inhibitors (Roche Diagnostics, Basel, Switzerland) and phosphatase inhibitors (Merck KGaA, Darmstadt, Germany). The concentration of total protein was determined using a bicinchoninic acid protein assay kit (Pierce; Thermo Fisher Scientific, Inc.) according to the manufacturer's protocol. Equal amounts of extracted protein samples $(20 \mu \mathrm{g})$ were separated by $10 \%$ SDS-PAGE and transferred onto a polyvinylidene difluoride membrane (EMD Millipore, Billerica, MA, USA). The membrane was blocked with $5 \%$ fat-free milk, followed by an overnight incubation at $4^{\circ} \mathrm{C}$ with the following primary antibodies: Mouse anti-human monoclonal AKT2 antibody (1:1,000 dilution; cat. no. sc-5270; Santa Cruz Biotechnology, Inc., Dallas, TX, USA) and anti-human monoclonal GAPDH antibody (1:1,000 dilution; cat. no. sc-69778; Santa Cruz Biotechnology, Inc.). After three washes with TBS containing $0.5 \%$ Tween, the membranes were probed with horseradish peroxidase-conjugated goat anti-mouse immunoglobulin G 
(1:5,000 dilution; cat. no. sc-2005; Santa Cruz Biotechnology, Inc.) for $2 \mathrm{~h}$ at room temperature. The bands were visualized with enhanced chemiluminescence Western Blotting Detection Reagent (GE Healthcare Bio-Sciences, Pittsburgh, PA, USA) according to the manufacturer's protocol. GAPDH was used as a loading control for AKT2. Band intensities were quantified using the FluorChem imaging system (Alpha Innotec, $\mathrm{GmbH}$, Kasendorf, Germany).

Bioinformatics analysis. In order to predict the putative targets of miR-296, a bioinformatics analysis was performed using TargetScan (http://www.targetscan.org/) and miRanda (http://www. microrna.org/microrna/).

Luciferase reporter assay. The wild-type (Wt1 and Wt2) pMIR-AKT2-3'UTR and mutant (Mut1 and Mut2) pMIR-AKT2-3'UTR were synthesized by Shanghai GenePharma Co., Ltd. HEK293T cells were seeded in 24-well plates at a density of $1.0 \times 10^{5}$ cells/well and transfected with miR-296 mimics or NC, and pMIR-AKT2-3'UTR Wt $(1,2)$ or pMIR-AKT2-3'UTR Mut $(1,2)$ using Lipofectamine 2000, according to the manufacturer's protocol. A total of $48 \mathrm{~h}$ post-transfection, the cells were collected and luciferase reporter assay was performed using the Dual-Luciferase Reporter Assay system (Promega Corporation, Madison, WI, USA) according to the manufacturer's protocol. Renilla luciferase activity was employed as an endogenous control for firefly luciferase activity. The assay was performed in triplicate.

Statistical analysis. Statistical analysis was performed using SPSS software version 17.0 (SPSS, Inc., Chicago, IL, USA). Data were expressed as the mean \pm standard deviation. Data were compared using Student's $t$-test or analysis of variance followed by Tukey's post-hoc test. $\mathrm{P}<0.05$ was considered to indicate a statistically significant difference.

\section{Results}

miR-296 expression in pancreatic cancer tissue and cell lines. RT-qPCR was used to measure miR-296 expression in human pancreatic cancer tissue samples and matched normal tissue samples (Fig. 1A). miR-296 expression in pancreatic cancer tissue was reduced compared with matched control tissue $(\mathrm{P}<0.05)$. The expression levels of miR-296 were also assessed in human pancreatic carcinoma cell lines and in the human normal pancreatic cell line HPDE6c7 (Fig. 1B). RT-qPCR revealed that miR-296 expression was significantly downregulated in all pancreatic cancer cell lines compared with HPDE6c7 cells $(\mathrm{P}<0.05)$.

Overexpression of miR-296 inhibits growth of PANC-1 and Capan-2 cells. In order to investigate the biological roles of miR-296 in pancreatic cancer, miR-296 mimics were used to upregulate miR-296 expression in pancreatic cancer cells. PANC-1 and Capan-2 cells, which exhibited the lowest miR-296 expression, were transfected with miR-296 mimics or NC. A total of $48 \mathrm{~h}$ post-transfection, the efficiency of transfection was confirmed via RT-qPCR (Fig. 2A). The results revealed that in PANC-1 and Capan-2 cell lines miR-296 levels were significantly increased post-transfection $(\mathrm{P}<0.05)$. A CCK8 assay was

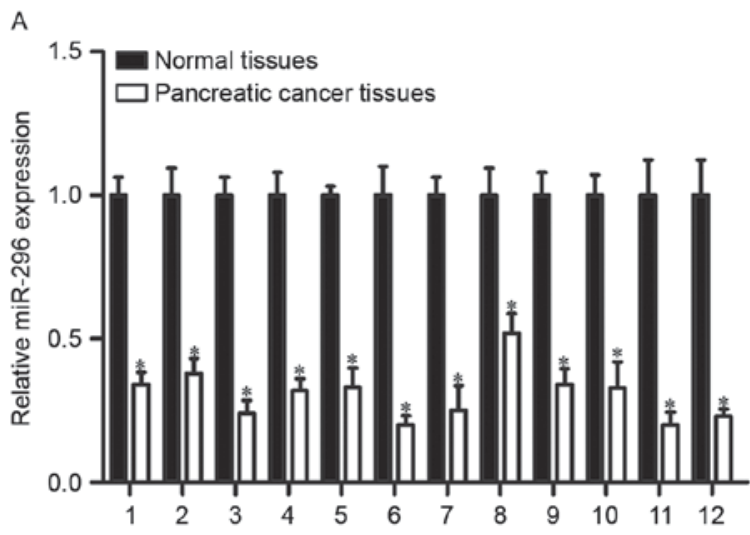

B

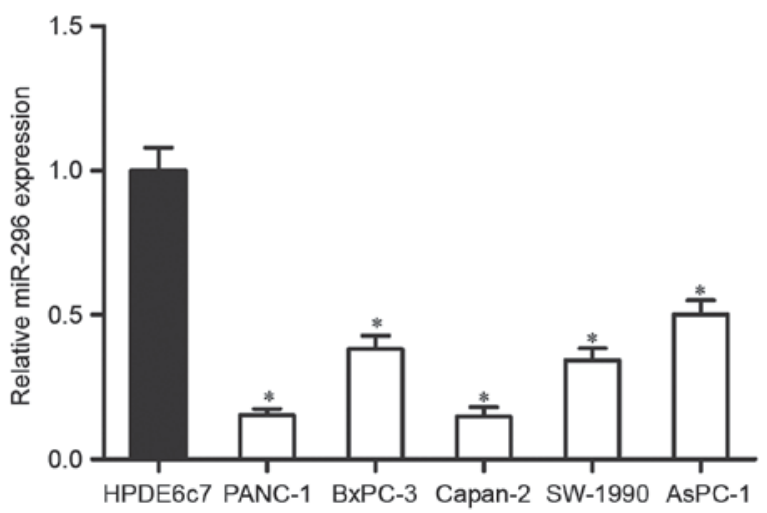

Figure 1. miR-296 was downregulated in pancreatic cancer tissues and cell lines. (A) miR-296 expression levels in 12 paired pancreatic cancer tissues and matched normal tissues were quantified by reverse transcription-quantitative polymerase chain reaction. ${ }^{*} \mathrm{P}<0.05$ compared with the normal tissues. (B) miR-296 expression levels in 5 pancreatic cancer cell lines and the human normal pancreatic cell line HPDE6c7 were also assessed. ${ }^{*} \mathrm{P}<0.05$ compared with the HPDE6c7 cells. miR-296, microRNA-296.

performed to investigate the effects of miR-296 on pancreatic cancer cell proliferation (Fig. 2B). The assay revealed that cell growth was significantly inhibited by miR-296 overexpression in PANC-1 and Capan-2 cells $(\mathrm{P}<0.05)$.

Overexpression of miR-296 inhibits migration and invasion of PANC-1 and Capan-2 cells. Transwell migration and invasion assays were performed to explore the effects of miR-296 overexpression on the migratory and invasive abilities of pancreatic cancer cells, which are pivotal for malignant metastasis (Fig. 3A and B). PANC-1 and Capan-2 cells transfected with miR-296 mimics exhibited significantly compromised migratory and invasive capabilities compared with NC-transfected cells $(\mathrm{P}<0.05)$. These findings suggested that miR-296 expression is downregulated in pancreatic cancer, and its overexpression may have tumor-suppressive properties through inhibiting the growth and metastasis of pancreatic tumors.

miR-296 directly targets AKT2 in pancreatic cancer. In order to explore the mechanism of action of miR-296 in pancreatic cancer, bioinformatics analysis was employed to identify potential target genes. Results suggested that the gene coding for AKT2 contains two possible miR-296 binding sites in its 3'UTR (Fig. 4A). A luciferase reporter assay was 

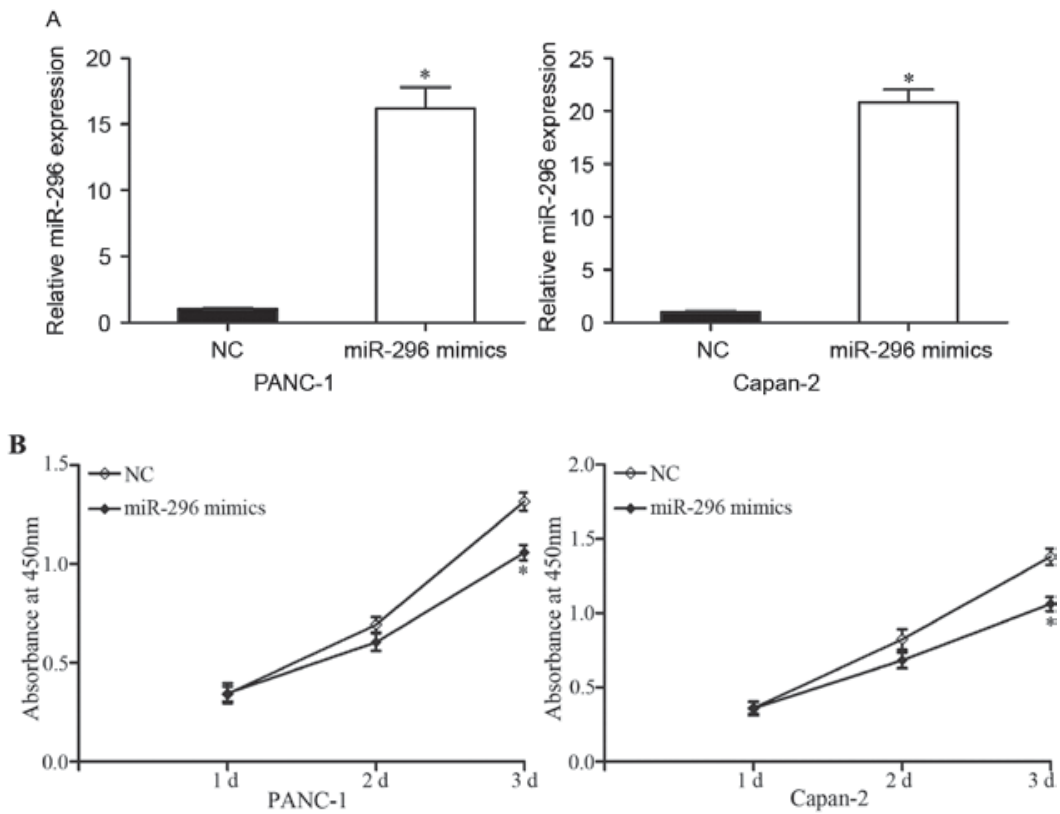

Figure 2. miR-296 inhibited growth of PANC-1 and Capan-2 cells. (A) Expression levels of miR-296 in PANC-1 and Capan-2 cells post-transfection with miR-296 mimics or NC were measured by reverse transcription-quantitative polymerase chain reaction. (B) CCK8 assay was performed to evaluate the effect of miR-296 on pancreatic cancer cell growth. In PANC-1 and Capan-2 cells, growth was significantly inhibited following transfection with miR-296 mimics. ${ }^{*} \mathrm{P}<0.05$ compared with the NC group. miR-296, microRNA-296; NC, negative control.
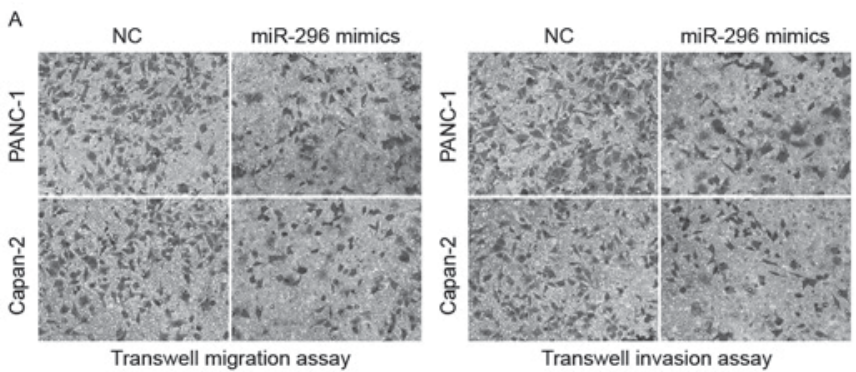

B
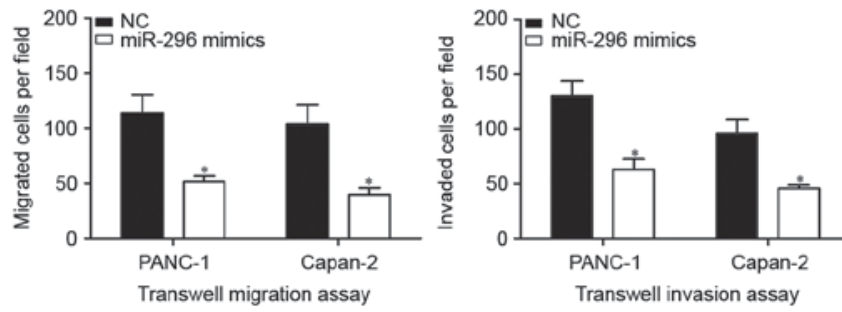

Figure 3. miR-296 inhibited the migratory and invasive abilities of PANC-1 and Capan-2 cells. (A) Transwell migration and invasion assays were performed to evaluate the effects of miR-296 on pancreatic cancer cell migration and invasion. (B) The numbers of migrated and invaded cells were significantly lower in PANC-1 and Capan-2 cells transfected with miR-296 mimics. "P<0.05 compared with the NC group. miR-296, microRNA-296; $\mathrm{NC}$, negative control.

performed to investigate whether miR-296 directly targeted AKT2 (Fig. 4B). The results revealed that miR-296 overexpression resulted in significantly reduced luciferase activity in the AKT2-3'UTR Wt 1 and AKT2-3'UTR Wt 2 groups $(\mathrm{P}<0.05)$, whereas mutation of the potential binding sites abolished the inhibitory effect of miR-296 overexpression. Furthermore, western blot analysis (Fig. 4C) demonstrated that miR-296 overexpression induced a significant decrease in AKT2 expression in PANC-1 and Capan-2 cells $(\mathrm{P}<0.05)$. However, miR-296 overexpression had no effect on AKT2 mRNA expression in PANC-1 and Capan-2 cells (Fig. 4D), indicating that miR-296 inhibits AKT2 expression at the post-transcriptional level. These results suggested that miR-296 may directly target AKT2 in pancreatic cancer cells.

RNA interference was used to silence the expression of AKT2 in PANC-1 and Capan-2 cells. The transfection efficiency was assessed by western blot analysis (Fig. 5A), which revealed that in both cell lines, transfection with AKT2 siRNA significantly decreased AKT2 expression levels $(\mathrm{P}<0.05)$. Post-transfection with AKT2 siRNA or NC siRNA, CCK8 and transwell migration assays were performed to investigate the effects of AKT2 on pancreatic cancer cell growth, migration and invasion (Fig. 5B-D). The results indicated that silencing the expression of AKT2 had similar inhibitory effects to miR-296 overexpression on the growth, migration and invasion of PANC-1 and Capan-2 cells $(\mathrm{P}<0.05)$. These results suggested that AKT2 may act as a direct target of miR-296 in pancreatic tumor cells.

\section{Discussion}

Elucidating the molecular mechanisms underlying pancreatic carcinogenesis and progression is crucial for developing novel therapeutic strategies (23). Pancreatic cancer is an aggressive cancer type, characterized by an accumulation of genetic mutations in various genes, including oncogenes and tumor suppressor genes $(24,25)$. miRNAs can negatively modulate gene expression via directly targeting specific mRNAs and inducing suppression of translation or cleavage (14). They are implicated in the development of human cancers, including pancreatic tumors $(26,27)$. Therefore, miRNAs hold great 
A

\begin{tabular}{|c|c|c|}
\hline AKT2 3' UTR Wt & 5 , & $\begin{array}{c}\text {...GUCCAGGGGCAGGCAGGGGCCCU } \\
|||||| \mid l\end{array}$ \\
\hline hsa-miR-296 & $3^{\prime}$ & UGUCCUAACUCCCCCCCGGGA \\
\hline AKT2 3' UTR mut & $5^{\prime}$ & $\begin{array}{l}\text {...GUCCAGGGGCAGGCACCCCGGGU } \\
\text { Site } 1\end{array}$ \\
\hline $\begin{array}{l}\text { AKT2 3' UTR Wt } \\
\text { hsa-miR-296 }\end{array}$ & $5^{\prime}$ & $\begin{array}{r}\text {...ACUCAUUUCAGACCAGGGGCCCU } \\
\text { UGUCCUAACUCCCCCCCGGGA }\end{array}$ \\
\hline AKT2 3' UTR mut & $5^{\prime}$ & $\begin{array}{l}\text {...ACUCAUUUCAGACCACCCCGGGU } \\
\text { Site } 2\end{array}$ \\
\hline
\end{tabular}

B
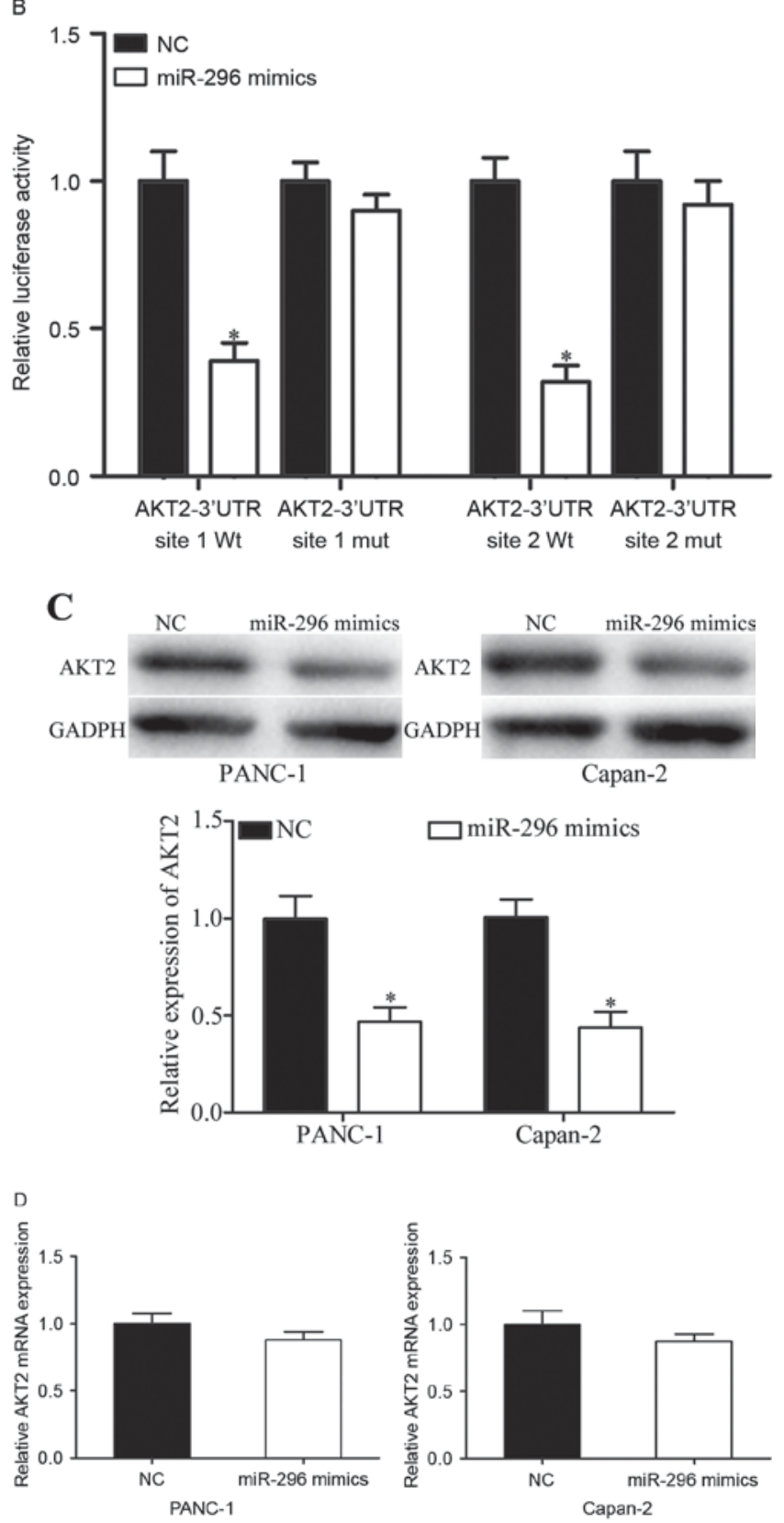

Figure 4. miR-296 directly targeted AKT2 in pancreatic cancer. (A) Predicted binding sites of miR-296 on the 3'UTR of AKT2. (B) miR-296 overexpression resulted in a significant reduction in luciferase activity in the AKT2-3'UTR Wt 1 and AKT2-3'UTR Wt 2 groups. However, mutation of the potential binding sites abolished the inhibitory effect of miR-296 in HEK293T cells. (C) miR-296 decreased AKT2 protein expression levels in PANC-1 and Capan-2 cells. (D) Reverse transcription-quantitative polymerase chain reaction indicated that AKT2 mRNA levels remained unaltered post-transfection with miR-296 mimics. ${ }^{*} \mathrm{P}<0.05$ compared with the NC group. miR-296, microRNA-296; 3'UTR, 3' untranslated region; Wt, wild-type; NC, negative control. potential as a novel therapeutic strategy for the treatment of pancreatic cancer.

The present study demonstrated that miR-296 is downregulated in pancreatic cancer tissue and cell lines. In addition, miR-296 overexpression can significantly inhibit the proliferation, migration and invasion of pancreatic cancer cells. Furthermore, AKT2 was revealed to be a direct target gene of miR-296 in pancreatic cancer. To the best of our knowledge, this is the first study to investigate the expression, biological role and mechanism of action of miR-296 in pancreatic cancer.

Recent studies suggested that miR-296 acts as a tumor suppressor in humans. miR-296 appeared to be downregulated in non-small-cell lung cancer, whereas miR-296 overexpression reduced cell viability by directly targeting Polo-like kinase 1 (28). Prostate cancer is characterized by low intratumoral miR-296 levels, whereas restoration of miR-296 expression was demonstrated to inhibit growth and invasion of prostate cancer cells through the downregulation of high mobility group protein HMGA1 (29). In addition, potentiated miR-296 expression decreased the proliferation and anchorage-independent growth of prostate cancer cell lines, through downregulation of Pin1, an isomerase whose upregulation may be implicated in carcinogenesis (30). In human breast cancer tissue, miR-296 levels appeared to be reduced, with low miR-296 expression being associated with reduced disease-free survival. Additionally, reduced miR-296 expression levels were significantly associated with an earlier spread of cancer in the overall series and with distant metastases. Furthermore, miR-296 has been demonstrated to decrease tumor growth in vivo via blockade of SCRIB, a protein possibly implicated in cancer progression (31). These findings suggested a fundamental role for miR-296 in human carcinogenesis and the progression of malignant tumors, and illustrate its potential as a therapeutic target for various types of cancer.

Conflicting studies suggested that miR-296 may function as an oncogene. In gastric cancer, miR-296 is upregulated in tumor tissue, whereas ectopic miR-296 expression can enhance cell growth by inhibiting cell cycle arrest and apoptosis, through suppression of the intestine-specific transcription factor Caudal-related homeobox 1 (32). The expression of miR-296 also appeared to be upregulated in esophageal squamous cell carcinoma, whereas miR-296 downregulation suppressed the proliferation of esophageal squamous cell carcinoma cells in vitro and in vivo by inhibiting the cell cycle regulators cyclin D1 and p27 (33). These conflicting findings may arise from fundamental differences between various cell types, and demonstrate the complexity of the mechanisms underlying tumorigenesis. The present study demonstrated that miR-296 was downregulated in pancreatic cancer, and overexpression of miR-296 inhibited growth, migration and invasion of pancreatic cancer cells.

In view of the key role miR-296 appears to serve in carcinogenesis, the present study further investigated the gene targets of miR-296 in an attempt to explore the mechanisms underlying pancreatic carcinogenesis. Bioinformatics analysis was employed to predict possible target genes for miR-296, and revealed that AKT2 contains two possible miR-296 binding sites in its 3'UTR. A luciferase reporter assay confirmed that AKT2 is a direct target gene of miR-296 in pancreatic cancer cells, whereas RT-qPCR and western blot analysis revealed 
A

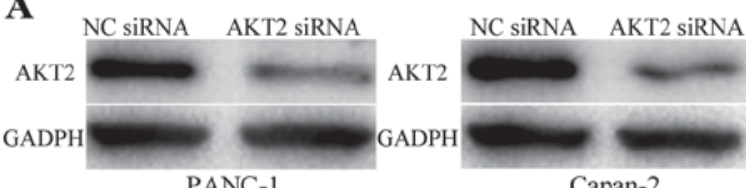

PANC-1

Capan-2

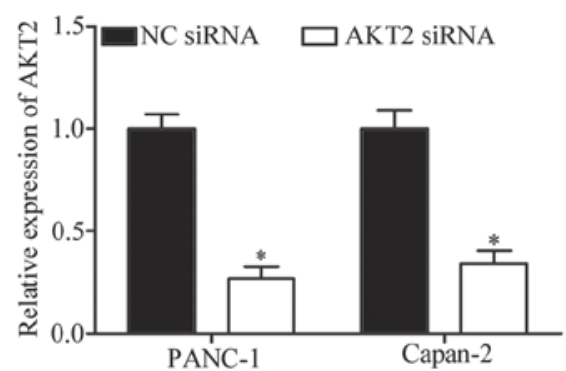

B
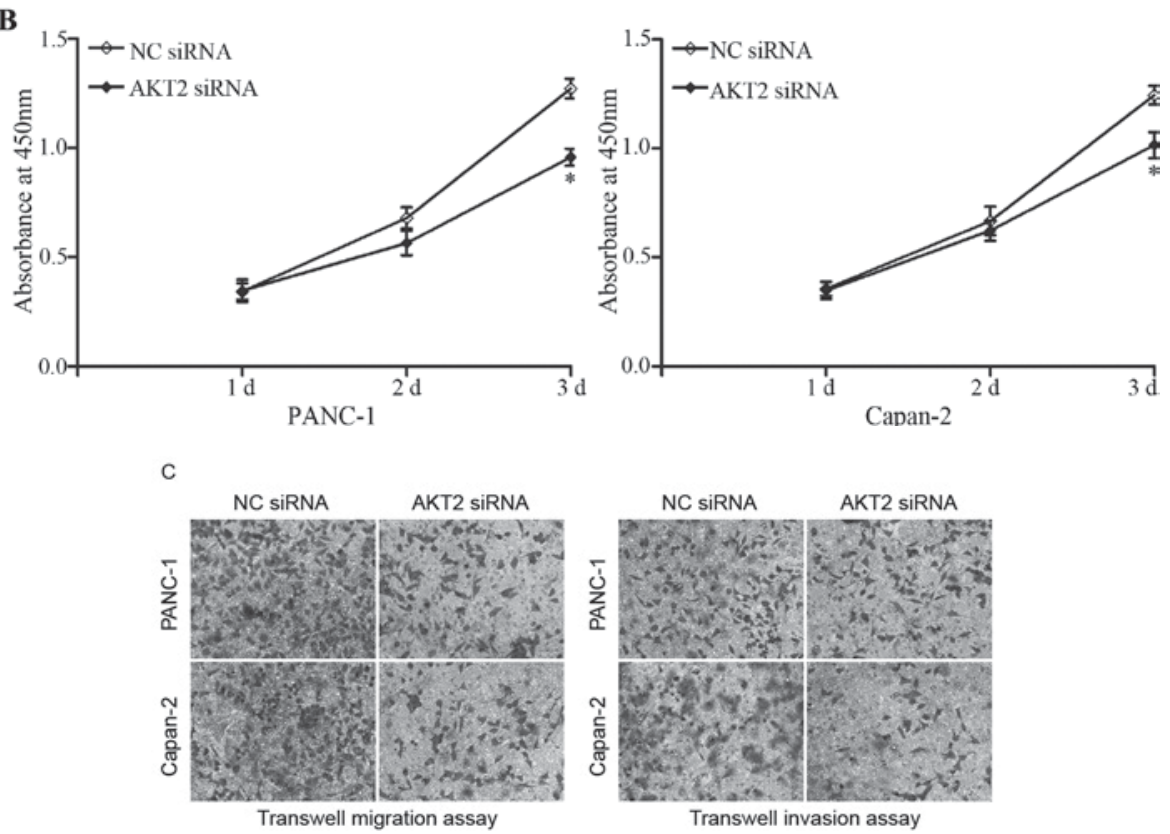

D
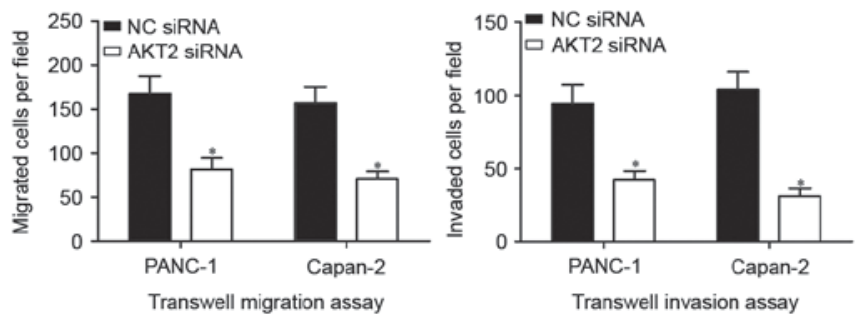

Figure 5. (A) AKT2 protein levels were measured post-transfection with AKT2 siRNA or NC siRNA by western blotting. (B) CCK8 assay was performed to evaluate the effect of AKT2 on pancreatic cancer cell growth. In PANC-1 and Capan-2 cells, growth was significantly inhibited following transfection with AKT2 siRNA. (C) Transwell migration and invasion assays were performed to evaluate the effects of AKT2 on pancreatic cancer cell migration and invasion. (D) The number of migrated and invaded cells was significantly lower in PANC-1 and Capan-2 cells transfected with AKT2 siRNA. "P<0.05 compared with the NC group. 3'UTR, 3' untranslated region; Wt, wild-type; NC, negative control; siRNA, small interfering RNA.

that miR-296 negatively regulates AKT2 expression at the post-transcriptional level. Finally, AKT2 silencing produced similar effects to miR-296 overexpression in pancreatic tumor cells. These results indicated that miR-296 may act as a tumor suppressor in pancreatic cancer through directly targeting and inhibiting AKT2 expression.

AKT is a conserved Ser/Thr kinase that participates in the phosphoinositide-3 kinase/AKT pathway, which regulates various cellular processes, such as proliferation, migration, invasion, metabolism and apoptosis $(34,35)$. Abnormalities in the AKT signaling pathway have been associated with several types of human cancer, including breast, prostate, lung and liver cancer, and glioblastoma $(36,37)$. AKT comprises three isoforms: AKT1, AKT2 and AKT3. In pancreatic cancer, AKT2 has been reported to be upregulated at the mRNA and protein level, whereas its catalytic activity is also potentiated $(38,39)$. 
These findings indicated a central role for AKT2 in pancreatic cancer pathogenesis. The findings of the present study identified AKT2 as a direct gene target of miR-296, indicating that the miR-296/AKT2 pathway may be a promising therapeutic target for the treatment of patients with pancreatic cancer.

In conclusion, the present study reported that miR-296 is downregulated in tissue from patients with pancreatic cancer and pancreatic carcinoma cell lines. These findings suggested that it may function as a tumor suppressor via inhibiting the growth, migration and invasion of pancreatic cancer cells. In addition, AKT2 was validated as a direct target of miR-296 in pancreatic cancer cells, suggesting a role for miR-296 as a novel therapeutic target for the treatment of pancreatic cancer.

\section{References}

1. Li D, Xie K, Wolff R and Abbruzzese JL: Pancreatic cancer. Lancet 363: 1049-1057, 2004.

2. Guo X and Cui Z: Current diagnosis and treatment of pancreatic cancer in China. Pancreas 31: 13-22, 2005.

3. Hao J, Zhang S, Zhou Y, Hu X and Shao C: MicroRNA 483-3p suppresses the expression of DPC4/Smad4 in pancreatic cancer. FEBS Lett 585: 207-213, 2011.

4. Siegel RL, Miller KD and Jemal A: Cancer statistics, 2017. CA Cancer J Clin 66: 7-30, 2017.

5. Fuchs CS, Colditz GA, Stampfer MJ, Giovannucci EL, Hunter DJ, Rimm EB, Willett WC and Speizer FE: A prospective study of cigarette smoking and the risk of pancreatic cancer. Arch Intern Med 156: 2255-2260, 1996.

6. Gapstur SM, Gann PH, Lowe W, Liu K, Colangelo L and Dyer A: Abnormal glucose metabolism and pancreatic cancer mortality. JAMA 283: 2552-2558, 2000.

7. Michaud DS, Giovannucci E, Willett WC, Colditz GA Stampfer MJ and Fuchs CS: Physical activity, obesity, height, and the risk of pancreatic cancer. JAMA 286: 921-929, 2001.

8. Dhayat SA, Abdeen B, Köhler G, Senninger N, Haier J and Mardin WA: MicroRNA-100 and microRNA-21 as markers of survival and chemotherapy response in pancreatic ductal adenocarcinoma UICC stage II. Clin Epigenetics 7: 132, 2015.

9. Couch FJ, Johnson MR, Rabe KG, Brune K, de Andrade M, Goggins M, Rothenmund H, Gallinger S, Klein A, Petersen GM and Hruban RH: The prevalence of BRCA 2 mutations in familial pancreatic cancer. Cancer Epidemiol Biomarkers Prev 16: 342-346, 2007.

10. Abbruzzese JL: The challenge of pancreatic cancer. Int J Gastrointest Cancer 33: 1-2, 2003.

11. Hezel AF, Kimmelman AC, Stanger BZ, Bardeesy N and Depinho RA: Genetics and biology of pancreatic ductal adenocarcinoma. Genes Dev 20: 1218-1249, 2006.

12. Shi C, Daniels JA and Hruban RH: Molecular characterization of pancreatic neoplasms. Adv Anat Pathol 15: 185-195, 2008.

13. Bhardwaj A, Singh S and Singh AP: MicroRNA-based cancer therapeutics: Big hope from small RNAs. Mol Cell Pharmacol 2 213-219, 2010.

14. Ambros V: The functions of animal microRNAs. Nature 431: 350-355, 2004

15. Boudreau RL, Jiang $P$, Gilmore BL, Spengler RM, Tirabassi R, Nelson JA, Ross CA, Xing Y and Davidson BL: Transcriptome-wide discovery of microRNA binding sites in human brain. Neuron 81: 294-305, 2014.

16. Gironella M, Seux M, Xie MJ, Cano C, Tomasini R, Gommeaux J, Garcia S, Nowak J, Yeung ML, Jeang KT, et al: Tumor protein 53 -induced nuclear protein 1 expression is repressed by miR-155 and its restoration inhibits pancreatic tumor development. Proc Natl Acad Sci USA 104: 16170-16175, 2007.

17. Iorio MV, Ferracin M, Liu CG, Veronese A, Spizzo R, Sabbioni S, Magri E, Pedriali M, Fabbri M, Campiglio M, et al: MicroRNA gene expression deregulation in human breast cancer. Cancer Res 65: 7065-7070, 2005.

18. Takamizawa J, Konishi H, Yanagisawa K, Tomida S, Osada H, Endoh H, Harano T, Yatabe Y, Nagino M, Nimura Y, et al: Reduced expression of the let-7 microRNAs in human lung cancers in association with shortened postoperative survival. Cancer Res 64: 3753-3756, 2004.
19. Naderi E, Mostafaei M, Pourshams A and Mohamadkhani A: Network of microRNAs-mRNAs interactions in pancreatic cancer. Biomed Res Int 2014: 534821, 2014.

20. Qin S,Zhu Y,Ai F,Li Y, Bai B, Yao W and Dong L: MicroRNA-191 correlates with poor prognosis of colorectal carcinoma and plays multiple roles by targeting tissue inhibitor of metalloprotease 3 . Neoplasma 61: 27-34, 2014.

21. Liu H, Xu XF, Zhao Y, Tang MC, Zhou YQ, Lu J and Gao FH: MicroRNA-191 promotes pancreatic cancer progression by targeting USP10. Tumour Biol 35: 12157-12163, 2014.

22. Livak KJ and Schmittgen TD: Analysis of relative gene expression data using real-time quantitative PCR and the 2(-Delta Delta C(T)) Method. Methods 25: 402-408, 2001.

23. He D, Miao H, Xu Y, Xiong L, Wang Y, Xiang H, Zhang H and Zhang Z: MiR-371-5p facilitates pancreatic cancer cell proliferation and decreases patient survival. PLoS One 9: e112930, 2014.

24. Vogelstein B and Kinzler KW: Cancer genes and the pathways they control. Nat Med 10: 789-799, 2004.

25. Feldmann G, Beaty R, Hruban RH and Maitra A: Molecular genetics of pancreatic intraepithelial neoplasia. J Hepatobiliary Pancreat Surg 14: 224-232, 2007.

26. Bai Z, Sun J, Wang X, Wang H,Pei H and Zhang Z: MicroRNA-153 is a prognostic marker and inhibits cell migration and invasion by targeting SNAI1 in human pancreatic ductal adenocarcinoma. Oncol Rep 34: 595-602, 2015.

27. Subramani R, Gangwani L, Nandy SB, Arumugam A, Chattopadhyay $\mathrm{M}$ and Lakshmanaswamy R: Emerging roles of microRNAs in pancreatic cancer diagnosis, therapy and prognosis (Review). Int J Oncol 47: 1203-1210, 2015.

28. Xu C, Li S, Chen T, Hu H, Ding C, Xu Z, Chen J, Liu Z, Lei Z, Zhang HT, et al: miR-296-5p suppresses cell viability by directly targeting PLK1 in non-small cell lung cancer. Oncol Rep 35: 497-503, 2016.

29. Lee KH, Lin FC, Hsu TI, Lin JT, Guo JH, Tsai CH, Lee YC, Lee YC, Chen CL, Hsiao M and Lu PJ: MicroRNA-296-5p (miR-296-5p) functions as a tumor suppressor in prostate cancer by directly targeting Pin1. Biochim Biophys Acta 1843: 2055-2066, 2014

30. Savi F, Forno I, Faversani A, Luciani A, Caldiera S, Gatti S, Foa P, Ricca D, Bulfamante G, Vaira V and Bosari S: miR-296/Scribble axis is deregulated in human breast cancer and miR-296 restoration reduces tumour growth in vivo. Clin Sci (Lond) 127: 233-242, 2014.

31. Wei JJ, Wu X, Peng Y, Shi G, Basturk O, Yang X, Daniels G, Osman I, Ouyang J, Hernando E, et al: Regulation of HMGA1 expression by microRNA-296 affects prostate cancer growth and invasion. Clin Cancer Res 17: 1297-1305, 2011.

32. Li T, Lu YY, Zhao XD, Guo HQ, Liu CH, Li H, Zhou L, Han YN, Wu KC, Nie YZ, et al: MicroRNA-296-5p increases proliferation in gastric cancer through repression of Caudal-related homeobox 1. Oncogene 33: 783-793, 2014.

33. Hong L, Han Y, Zhang H, Li M, Gong T, Sun L, Wu K, Zhao Q and Fan D: The prognostic and chemotherapeutic value of miR-296 in esophageal squamous cell carcinoma. Ann Surg 251: 1056-1063, 2010

34. Agarwal E, Brattain MG and Chowdhury S: Cell survival and metastasis regulation by Akt signaling in colorectal cancer. Cell Signal 25: 1711-1719, 2013.

35. Kang B, Hao C, Wang H, Zhang J, Xing R, Shao J, Li W, $\mathrm{Xu} \mathrm{N}, \mathrm{Lu} \mathrm{Y}$ and Liu S: Evaluation of hepatic-metastasis risk of colorectal cancer upon the protein signature of PI3K/AKT pathway. J Proteome Res 7: 3507-3515, 2008.

36. Buontempo F, Ersahin T, Missiroli S, Senturk S, Etro D, Ozturk M, Capitani S, Cetin-Atalay R and Neri ML: Inhibition of Akt signaling in hepatoma cells induces apoptotic cell death independent of Akt activation status. Invest New Drugs 29: 1303-1313, 2011.

37. Xu N, Lao Y, Zhang Y and Gillespie DA: Akt: A double-edged sword in cell proliferation and genome stability. J Oncol 2012: 951724, 2012.

38. Cheng JQ, Ruggeri B, Klein WM, Sonoda G, Altomare DA, Watson DK and Testa JR: Amplification of AKT2 in human pancreatic cells and inhibition of AKT2 expression and tumorigenicity by antisense RNA. Proc Natl Acad Sci USA 93: 3636-3641, 1996

39. Altomare DA, Tanno S, De Rienzo A, Klein-Szanto AJ, Tanno S, Skele KL, Hoffman JP and Testa JR: Frequent activation of AKT2 kinase in human pancreatic carcinomas. J Cell Biochem 87: 470-476, 2002. 